\section{THE SHAPES OF LEAVES}

\section{II.-Extreme and Intermediate Types}

WHERE access to carbonic acid and sunlight is habitually unimpeded by the competition of other plants in any direction, the leaf of each species tends to assume a completely rounded form; the conditions are evenly distributed on every side of it. Such absolute freedom to assume the fullest foliar perfection is best found on the surface of the water. Hence most waterplants which have leaves lolling on the surface assume a

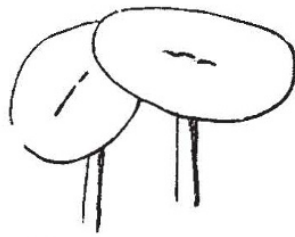

FIG. 10.-Lemna miror.

more or less distinctly rounded shape, the venation and other details remaining in accordance with the ancestral habit. Foliage of this character is found in the waterlilies and many other aquatic plants. The little entire lenticular fronds of the common duckweed, Lemna minor (Fig. 10), which coats all our small ponds and ditches, form an excellent example of the type in question. Here the shape is almost orbicular; the edge is entire; and the smallness of each separate frond is due to the minute. ness of the plant and the obvious necessities of its situation. In the waterlilies we get a similar example on a much

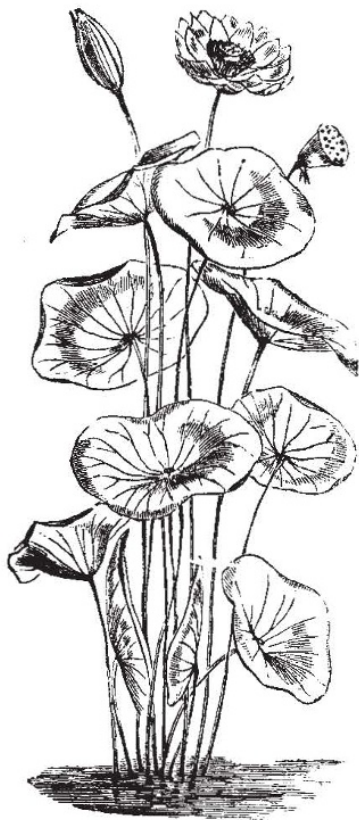

FIG. It. -Nelumbium speciosum.

larger scale, for these plants recline on broader and more permanent sheets of water, and draw nourishment from their large rhizome, sunk securely in the mud beneath, and anrually accumulating a rich store of foodstuffs for the growing foliage.

Mr. Herbert Spencer (by whose kind permission two accompanying diagrams are copied frcm "The Frinciples of Biology") foints out a distinction between the shapes adopted by such plants, according to their relations to a central axis. In the sacred lotus, Nelumbium speciosum I Contirued from p. 442.
(Fig. II), the leaves grow up on long and independent footstalks, without definite subordination to any such axis; and they therefore assume an almost perfectly symmetrical peltate form. In the Victoria regia (Fig. 12) the footstalks, though radiating almost horizontally from a centre, are long enough to keep the leaves quite remote from one another; and here they assume an almost symmetrically peltate shape, but with a bilateralness indicated by a long seam over the line of the footstalk. The leaves of our own white waterlily, Nymphaa alba (Fig. 13), are more closely clustered, and have less room to expand transversely than longitudinally; hence they are somewhat longer tban broad, and have a cleft where the Victoria regia has only a seam. Limnanthemum shows the same type on a smaller scale.

Among land plants, the conditions under which leaves

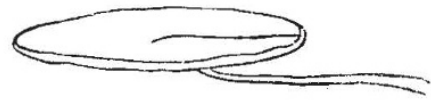

FIG. 12.-Victoria regia.

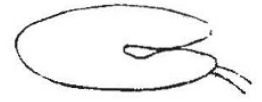

FIG. 13. - Nymphaa alba. can fill out to the full rounded shafe occur less frequently than among floating aquatic species; still, even here a very interesting set of gradations may be observed. The best example of all is that given by the common American May-apple, Podophyllum peltatum, where the separate radical leaves grow straight up from a stout rootstock on very thick and tall stalks, so as to overshadow all the other vegetation; and they assume a regular, circular, feltate form, exactly like a Japanese parasol. The radical leaves of our own English Cotyledon umbilicus (Fig. 14), springing from a perennial rootstock, for the most part on bare walls or unoccupied hedgerows, are able similarly to expand without interference, and catch carbonic acid and sunlight to their bearts' content. Hence they are orbicular and peltate, though they retain the characteristic crenate edge of most flat-leaved Crassulaceæ.

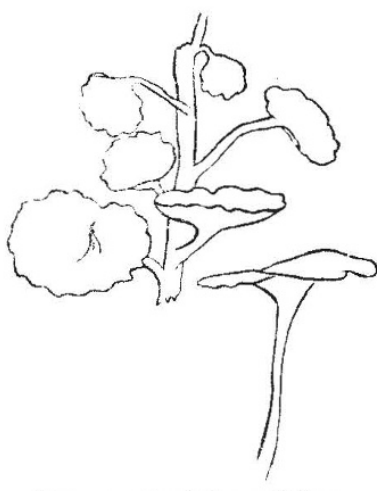

Fig. x4.-Cotyledon umbilicus.

But the upper leaves, springing from the flower-stalk, are more bilateral, as sbown in the figure, though even these round out to a more or less orbicular form, owing to their exceptional access to air and light. The so-called garden nasturtium, Tropceolum majus, with leaves growing out at right angles into open space, has also peltate leaves, as has likewise the usually aquatic Hydrocotyle.

When the plant sends up leaves from a rich buried rootstock, so tall as to overshadow the surrounding vegetation, but subordinated to a common centre, they usually assume the reniform shape. This type is particularly well seen in the various coltsfoots-for example, in Tussilago farfara, $T$. petasites, and $T$. fragrans (Fig. I5). Similar types occur in Asarabacca, and in the marsh marigold, Calthapalustris. Extremely similar to the leaf of Caltha, though on a smaller scale, is that of one true buttercup, 
Ranunculus ficaria, the lesser celandine, which produces its foliage in early spring from buried tubers, and so anticipates other plants, having the air all to itself for a couple of months, after which it gets overshadowed by later comers. The same type recurs pretty closely in the radical leaves of its allies, R.auricomus and $R$. parviflorus, as also somewhat more remotely in the ivy-leaved crowfoot, $R$. hederaceus, which creeps, unimpeded, over soft mud. Many early spring plants have lower or radical leaves at least of this reniform type, because they grow in comparatively unoccupied ground. As an example, take ground-ivy, Nepeta glechoma (Fig. I6). The violets represent a closely similar case. Many of these plants,

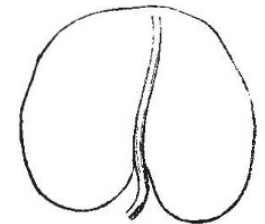

Fig. 15.-Typical leaf of Tussilago genus.

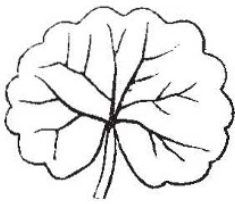

FIG. x6.-Nepeta glecoma. however, produce later on, when foliage grows thicker, much more lanceolate leaves. In the burdocks, docks, \&c., this type is persistent.

On the other hand, where the distribution of carbonic acid is most scanty, or where the competition is fiercest, or where the competing plants are supplied with no reserve to enable them to send up shoots which orertop their competitors, immense subdivision into leaflets takes place, and these leaflets are often almost or quite filiform. The extent to which leaflets are subdivided depends upon the relative paucity of carbon in their environment; the general resulting form depends mainly upon the inherited type of venation. Among submerged aquatic plants, the

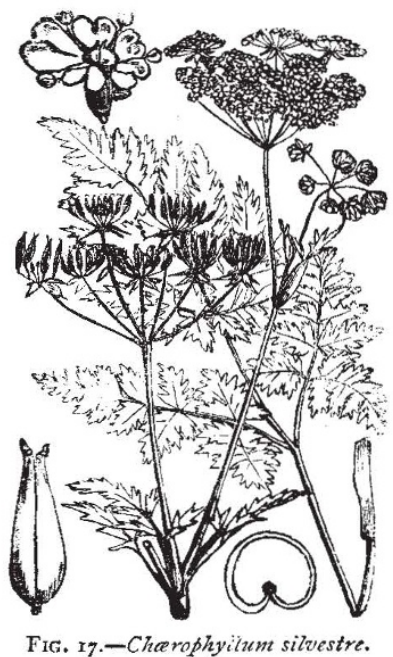

filiform condition is habitual, because carbonic acid is so comparatively scarce in water. Among British species, the water violet, Hottonia palustris, is a good example. All terrestrial primroses have undivided foliage; but in Hottonia the leaves, still preserving the pinnate character of the venation, as in the common primrose, are cut into very deep segments, forming a close mass of narrow, linear, waving threads, more like a Chara than a flowering plant at a first glance. Utricularia shows the same result with a different ground-plan. In Myriophyllum, water milfoil, we have whorls of leaves each minutely subdivided into hair-like pinnate segments, and moving freely through their still ponds in search of stray carbon particles diffused in the water. Hippuris has the separate leaves undivided, but attains the same result by crowding its long, thin, linear blades in whorls of ten or twelve, so as closely to resemble an Equisetum. - Our common Ceratophyllum looks at first sight much like water-milfoil, but here the whorled leaves, instead of being pinnately divided, are repeatedly forked into subulate or capillary segments, the result of a branching rather than of a pinnate venation. Other instances will occur at once to every botanist.

On land we get very much the same condition of things

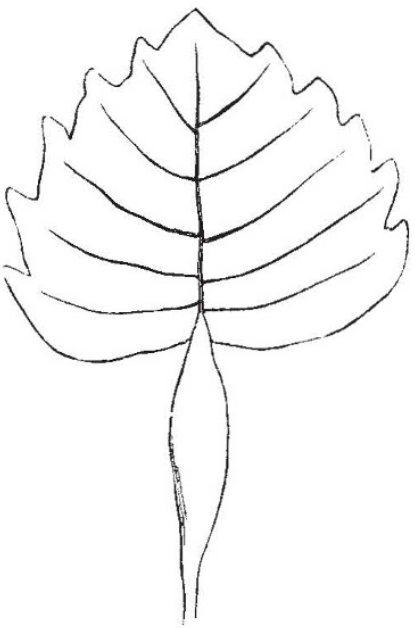

FIG. r8.-Floating leaf of Trapa natans.

in the fierce competition that goes on for the carbon of the air between the small matted undergrowth of every thicket and hedgerow. The common weedy plants, and especially the annuals or non-bulbous perennials, which grow under such conditions, cannot afford material to push broad leaves above their neighbours' heads, and they are therefore compelled to fight among themselves for every passing particle of carbon. Hence they are usually very minutely subdivided, though in a less waving and capillary manrier than the submerged species; their

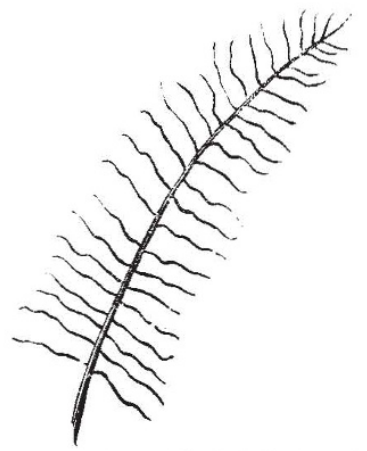

FIg. 19.-Submerged leaf of Trapa natans.

leaflets are oftener flat, and definitely exposed on their upper surface to the sunlight. That essentially weedy family, the Umbellates, contains a great number of such highly segmented hedgerow leaves. Common wild chervil, Chorophyllum silvestre (Fig. I7), forms a familiar example : other cases are C. temulum, Sison Amomum, many Carums, Enanthes, Pimpinellas, Daucus, Caucalis, \&c., all of which belong by habit to greatly overgrown localities. Compare these with the free-growing, almost orbicular, radical leaves of Astrantia and Sanicula, in 
the same family; or with the still freer peltate leaves of Hydrocotyle; or again with the divided but more broadly segmented leaves of those tall open-field species, cowparsnip, Heracleum sphondylium, and Alexanders, Smyrnium olusatrum, which have only to compete against the grasses and clovers; or, finally, with the large waterside forms, Apium graveoleus, Sium latifolium, and Angelica silvestris. So, too, take the much segmented herbRobert, Geranium Robertianum, of all our hedgerows, growing side by side with the like-minded chervils and carrots, and compare it with that persistent rounded geraniaceous type which recurs, not only in our English G. molle, \&c., but even in many exotic Pelargoniums. Among composites the crowded type is best exemplified by that thicket weed, milfoil, Achillea millefolium, with its infinite number of finely-cut, pinnatifid segments; while in the taller but closely-allied sneezewort, Achillea ptarmica, growing on high open pastures, we get the same general type in outline and venation, only entire save for the slight serrations along its edge. In tansy, Tanacetum vulgare, also a hedgerow plant, the same type as milfoil recurs on a far larger and handsomer scale. Compare these with coltsfoot and burdock, or even with the tall eupatory and the tufted, close-packed daisy. Other good miscellaneous instances of the weedy type are fumitory, Corydalis, moschatel, the camomile group, \&c. ; while among larger cryptogams the majority of thicket ferns display an equally marked subdivision of the fronds and pinnæ. It may be added that highly civilised countries like En oland are particularly rich in these subdivided types of foliage, owing to the predominance of hedgerows and of tall grasses.

As in the submerged plants, so in the matted terrestrial undergrowth, whorling of linear leaves may practically answer the same purpose as minute segmentation. Some plants solve the difficulty of catching stray carbon in the one way, and some solve it in the other. Each adopts the easiest modification of its own ancestral type. For example, take the stellate tribe. Their tropical allies, the larger Rubiaceæ, have simple, usually entire, opposite leaves, with interpetiolar stipules. In the small, weedy, northern forms however, the interpetiolar stipules have grown out into linear leaf-like foliar organs, forming with the true leaves an apparent whorl of six members. Sometimes, too, the whorl is enlarged to as many as eight leaves, and sometimes reduced to four. These thick whorls of small leaves, always well turned outward to the sunlight, have become practically analogous in their action to minutely segmented leaflets, in our English Galiums, Asperulas, and Sherardia. Two of them at least, $G$. mollugo and $G$. aparine, are extremely common hedgerow plants. Compare them with the broad-leaved free-climbing Rubia peregrina, which has only four large members to each whorl.

Among monocotyledons, where (as will be afterwards explained) the type is given by the peculiarity of the cotyledon and governs the venation, minute subdivision is replaced in the matted undergrowth by single, linear, lanceolate blades, which answer the selfsame purpose in the long run. The grasses, sedges, and woodrushes are sufficient examples. Here the numerous leaves, all long and narrow, and all with long thin flower stems, strive to overtop one another, and run up side by side to a considerable height. They may be compared with the large rich leaves of the bulbous lilies, tulips, amaryllids, and orchids. In both cases the type is the same, but the development is different. Plants that consort much with the grasses, as for example ribwort plantain, though wholly unlike in type, are apt to be drawn up and assimilated to them, not merely in general character, but even in venation and mode of fertilisation. Other grass-like dicotyledons are found among the Polygonums, Armerias, Bupleurums, pinks, \&c., all under similar circumstances to those of the grasses themselves.
Intermediate types between these two extremes of entire obicularity and minute subdivision occur everywhere. Compare, from this point of view, the common meadow buttercups, which grow in fully occupied meadows, with Caltha and the lesser celandine. Compare, again, the mallows on the one hand with the peas on the other, or the docks with the crucifers. Throughout these intermediates, various stages can be easily observed. For example, the South European water-chestnut, Trapa natans, beautifully illustrates the gradations which have finally given us our own Hippuris and Myriophyllum from an Onagraceous or Sa vifrage ancestor. It has a number of floating leaves (Fig. I8) supported by bladder-like petioles filled with air, and arranged radially round the stem. Hence, though large and spreading, they are distinctly bilateral, and they do not interfere with one another's food supply. But the submerged leaves (Fig. I9, very diagrammatic) are mere pinnate skeletons of the venation, waving about in the water below. Among monocotyledons, the Potamogetons show us some very instructive similar cases, altered in character by the peculiarities of the very persistent monocotyledonous foliar type. In the floating leaves of $P$. natans they come as near the waterlilies as a monocotyledon can reasonably expect to do; in $P$. pectinatus, the wholly submerged leaves look like long blades of grass, proceeding from the thread-like stem 3 .

Less minutely subdivided than the hedgerow plants are a large class of somewhat weedy forms, well typified by our smaller English crucifers. These are often pinnately divided to a considerable extent, as in Cardamine hirsuta and Senebiera didyma. Compare them with the taller kinds, such as cabbage and charlock. Much the same type reappears in the lowly forms of Papilionacex, as for example in Anthyllis, Astragalus, Ornithopus, Hippocrepis, \&c. On the other hand, in the tall climbing Vicias, and still more in Lathyrus, the leaflets, having more carbon, more sun, and less competition, fill out rounder, and generally decrease in number, the upper ones being transformed into tendrils. But in the very grass-encumbered clover-like types, Ononis, Medicago, Melilotus, Trigonella, and, above all, Trifolium itself, the leaflets are dwarfed and reduced to three, the lower members being suppressed, and only the three terminal ones left, so as to raise them on a long footstalk up to the air and sunshine. Compare the very similar leaflets of wood-sorrel. Again, look at the various conditions under which the following Rosaceous plants grow: pear, blackthorn, strawberry, cinquefoil, silver-weed, great burnet, salad burnet, and compare some of them with clover, lady's-fingers, and Hippocrepis. The comparison tells its own tale at once.

Finally, we must briefly allude to a large class of tufted plants, usually with entire, ovate, obovate, or ovatelanceolate leaves, which grow in a rosette from a centre, and insure themselves a good supply of carbon and of light by keeping under all competitors with their close tufts. Of these, our common daisy forms an excellent example: notice the tight way it fits itself against the ground so as to prevent grass from growing beneath it. Another good case in point is Plantago media: compare form and habit with those of $P$. major and $P$. lanceolata. To the same class, more or less, may be referred Arabis thatiana and many crucifers, London Pride, the common primrose, Hieracium pilosella, \&c. ; and, with more pinnate, lyrate, or prickly leaves, the young thistles, and the radical foliage of many ligulate composites.

The shapes of leaves thus depend upon the average surrounding conditions, modifying a given ancestral type. How these ancestral types themselves were first developed we shall have to inquire in our next paper.

GRANT ALLEN

( To be continued.) 